\title{
Como escrever bem
}

On writing well

Frederico Dollo Linardi ${ }^{1}$

Pontifícia Universidade Católica do Rio Grande do Sul, Escola de Humanidades, Programa de Pós-Graduação em Letras, Porto Alegre, RS, Brasil.

\section{RESENHA DA OBRA:}

ZINSSER, William. Como escrever bem. Trad. Bernardo Ajzenberg. São Paulo: Três Estrelas, 2017.

Desde sua primeira edição americana, On writing well (1976) tornou-se uma referência de escrita de não ficção para escritores, estudantes e pessoas de diversas áreas que trabalham de alguma maneira com a escrita e desejam aprimorar sua redação. Ao longo das três décadas seguintes ao seu lançamento, o livro ganhou oito reedições, respeitando as evoluções da própria linguagem e as influências de novas tecnologias. Com isso, manteve-se como uma constante fonte de consulta e manual de escrita e teve sua mais recente edição na língua inglesa em 2006, quando se comemorou seu trigésimo aniversário.

William Zinsser escreveu esse livro após a experiência como jornalista no começo de sua carreira e depois de ter iniciado suas oficinas de escrita de não ficção na Universidade de Yale, onde costumava intercalar informações técnicas com exercícios práticos aos iniciantes deste gênero (DIXLER, 2009). Após quatro anos de ensino e publicações de breves artigos em revistas, ele se dedicou a escrever On writing well que, até a primeira década de 2000, havia vendido 1,5 milhão de exemplares. Além deste, Zinsser é autor de outros 18 títulos que variam entre guias de escrita - como Writing to learn e Writing about your life - e a própria prosa de não ficção, em diferentes temáticas como o jazz, em Mitchell \& Ruff; e narrativa de viagem, em American Places. 
A primeira obra do autor publicada no Brasil é Como escrever bem, traduzida a partir da última edição do livro, datada de 2006, e que vem a ser a última versão do próprio autor, falecido em 2015. Em 2017 o livro ganhou sua primeira publicação no Brasil, pela Editora Três Estrelas, com a tradução de Bernardo Ajzenberg, já conhecido por sua experiência em traduções do inglês, francês e espanhol (tendo sido já agraciado com o Prêmio Jabuti 2010 em melhor tradução, pela obra Purgatório, de Tomás Eloy Martínez). Ajzenberg é também autor de dez romances, entre eles $A$ gaiola de Faraday, premiado pela Academia Brasileira de Letras em 2002, Minha vida sem banho, vencedor do Prêmio Casa de las Americas em 2015, e o mais recente Gostar de ostras, de 2017. Entre os livros de não ficção traduzidos por Ajzenberg estão Dez dias que abalaram o mundo, do norteamericano John Reed (Companhia das Letras, 2010); Como os ricos destroem o planeta, do francês Hervé Kempf (Editora Globo, 2010); e As casas que fizeram história e seus arquitetos, do francês Didier Cornille (Cosac Naify, 2014).

Apontando para o mesmo sucesso que teve com sua versão original, a tradução brasileira de On writing well já conta com sua segunda reimpressão até o momento da escrita desta resenha. Assim como na língua inglesa, as técnicas e orientações compartilhadas por Zinsser são de grande contribuição aos leitores/escritores brasileiros, ponderando-se alguns ajustes e adaptações necessárias para manter a coerência com as diferentes conjunturas gramaticais e linguísticas. Vejamos a seguir um panorama dessa tradução, assim como algumas perdas e soluções encontradas para a publicação desse livro no Brasil.

O livro é composto por quatro partes que dividem os capítulos entre os conceitos: "Princípios"; "Métodos"; “Gêneros"; e "Atitudes". Na primeira parte o leitor se depara com os capítulos: "A negociação"; "Simplicidade"; "Excessos"; "Estilo"; “O público"; "Palavras”; e "Usos". Na segunda, o autor organiza o conteúdo em: "Unidade"; "O lide e o final"; e "Miscelânea". Na terceira, dedicada aos gêneros, o leitor da edição brasileira encontra: "A não ficção como literatura"; "Escrever sobre pessoas: A entrevista"; "Escrever sobre lugares: A reportagem sobre viagens"; "Escrever sobre si mesmo: Memórias". Por fim, na quarta parte, os capítulos: "O som da sua voz"; "Prazer, medo e confiança"; "A tirania do produto final"; "Decisões de um escritor"; "Escrever histórias de família e memórias"; "Escreva tão bem quanto puder".

Comparado ao mercado literário americano, o brasileiro ainda sofre certa defasagem quando se trata de guias de Escrita Criativa, especialmente em narrativas de não ficção. Dessa forma, uma publicação com a importância de On writing well é relevante tanto pela qualidade quanto pelo ineditismo de seu conteúdo, assim como pelos pontos de vista do autor. Mesmo assim, a edição brasileira excluiu cinco capítulos da terceira parte, dedicada aos gêneros. Ficaram de fora "Science and Technology"; "Business Writing: Writing in your Job"; "Sports"; "Writing About the Arts: Critics and Columnists"; e "Humor". A nota na ficha técnica referente a essa redução na edição brasileira também aponta a supressão de dois itens do capítulo "Bits and pieces" (traduzido por "Miscelânea"): "Contractions" " "That and Which". Neste caso, as exclusões se explicam pela própria diferença idiomática, pois não faria sentido trazer ao escritor da língua portuguesa questões gramaticais referentes ao inglês.

Ao contrário destes, no entanto, o leitor da tradução perde o conteúdo dos capítulos dedicados à ciência e tecnologia, escrita sobre negócios, esportes, coluna e crítica de arte, e humor. A ausência de tais capítulos representa um prejuízo tanto quantitativo (eles ocupam 80 páginas no original), como qualitativo. "Mas dizer o motivo pelo qual você acha uma peça de teatro boa, com palavras que não façam sua opinião soar banal, é uma das tarefas mais difíceis deste trabalho" (2006, p.194, tradução 
nossa) ${ }^{1}$, aponta Zinsser no capítulo sobre a escrita das artes. "O humor é a arma secreta do escritor de não ficção. É secreta, pois muitos poucos escritores percebem que o humor é geralmente a melhor ferramenta - e, às vezes, a única - para trazer uma questão importante" (2006, p. 207, tradução nossa $)^{2}$ - assim o autor abre o capítulo sobre o humor na escrita. Também seria de grande valia aos escritores e jornalistas brasileiros terem contato com a escrita sobre áreas específicas e que geralmente sofrem pela falta de originalidade temática e de abordagem, como as matérias sobre esportes, ou pela superficialidade, como as de ciência e tecnologia.

Por fim, o capítulo que poderia ser um grande apoio às pessoas que não se dedicam profissionalmente à escrita, mas têm que praticá-la cotidianamente no trabalho, "Business Writing", também faz falta. Nele, o autor mostra, sempre por meio de exemplos - como acontece ao longo da obra - como um texto bem escrito e humanizado (e menos pretensioso) facilita a comunicação e o relacionamento entre seres humanos com vínculos institucionais, como mensagens de diretores de escola destinadas aos pais de alunos.

O título On writing well foi traduzido por Como escrever bem, comunicando ao leitor brasileiro a ideia de um texto no estilo 'manual de escrita', talvez para alcançar maior interesse público, ao invés de trazer uma tradução mais literal como "Sobre escrever bem", mantendo inclusive a tradição dos títulos que remontam aos tratados clássicos em latim.

No original, a ênfase é sustentada apenas no subtítulo "The classic guide to writing nonfiction", ao passo que na tradução é utilizada a palavra "manual", trazendo a certeza de que o livro é verdadeiramente um manual

\footnotetext{
Do original: But to say why you think a play is good, in words that don't sound banal, is one of the hardest chores in the business.

2 Do original: Humor is the secret weapon of the nonfiction writer. It's secret because so few writers Do original: Humor is the secret weapon of the nonfiction writer. It s secret because so few writers
realize that humor is often their best tool - and sometimes their only tool - for making an important point.
}

de escrita: "o clássico manual americano de escrita jornalística e de não ficção". A complementação das informações comprova o cuidado editorial em orientar o leitor de maneira objetiva. O livro é um manual voltado a escritores que buscam orientações específicas sobre o gênero de não ficção. Além disso, foi incluída a palavra "jornalística”, trazendo a ideia de separação conceitual entre o gênero jornalístico, no qual cabem os breves perfis, as reportagens especiais e a crônica; e o não ficcional mais abrangente, um tipo de prosa que pode se estender aos gêneros como o de memórias.

Tal separação de conceitos, porém, pode soar arbitrária, pois conhecemos excelentes textos jornalísticos que assumem o caráter literário, sendo o resultado de técnicas narrativas da literatura e da ética jornalística (de apuração, pesquisa, entrevistas e relatos factuais) para narrar sobre acontecimentos e pessoas reais. Alguns desses exemplos compõem os capítulos do livro, com textos de autores e autoras como Joan Didion e John McPhee, quando Zinsser aponta determinadas técnicas da narrativa de não ficção.

O trabalho de diagramação da edição brasileira é bem realizado, de modo que proporciona conforto e dinâmica na leitura, com bons espaçamentos e respiro de margens. Porém, existe uma limitação ilustrativa no capítulo "Simplicidade" (Simplicity). No original, Zinsser, para elucidar a elaboração de um texto contendo releituras e reescritas, compartilha parte do manuscrito do próprio capítulo. É uma maneira interessante de entender este processo. Por mais que não seja em português e que fosse impossível traduzir um manuscrito sem que ele perdesse sua originalidade, ainda seria possível observar os elementos genéticos do texto como as rasuras, privilégio quase nunca acessível ao leitor final.

Mais do que suscitar um cotejo curioso, as duas páginas de textos manuscritos da edição americana exemplificam o árduo trabalho que é a escrita e, sendo este processo o maior interesse do leitor de Como escrever 
bem, elas funcionam como uma comprovação material que o próprio Zinsser comenta no final deste mesmo capítulo. "If you find that writing is hard, it's because it is hard.", o que foi bem traduzido com a mesma clareza do itálico em "is" pelo uso da palavra "mesmo": "Se você acha difícil escrever, é porque é mesmo difícil” (ZINSSER, 2017, p. 23).

Um dos desafios de se traduzir um livro sobre escrita são os exemplos de usos de linguagem e construções ortográficas que não têm relação ou correspondência direta com o idioma de chegada. Como já mencionado, os trechos "Contractions" e "That and Which" perderiam o sentido e seriam inaplicáveis pelo escritor brasileiro. No entanto, existem outros trechos do livro onde o sentido se mantém, apesar das palavras exigirem correspondências alternativas à tradução literal. São os casos de neologismos, estrangeirismos, jargões e outros termos populares problematizados em capítulos como "Palavras" (Words) e "Usos" (Usage).

Em algumas situações Ajzenberg recorre à necessária nota explicativa, especialmente quando se trata de termos que no inglês funcionam com duplo sentido ou em colocações em que Zinsser se utiliza de ironia e jogos de palavras. Em um mesmo parágrafo podemos encontrar exemplos que exigiram escolhas e posicionamento do tradutor:

Earlier I mentioned an incident of college students hassling the administration, and in the last chapter I described myself as a word freak. Here are two fairly recent arrivals. "Hassle" is both a verb and a noun, meaning to give somebody a hard time, of the act of being given a hard time, and anyone who has ever been hassled for not properly filling our Form 35-BX will agree that the word sounds exactly right. "Freak" means an enthusiast, and there's no missing the aura of obsession that goes with calling someone a jazz freak, or a chess freak, or a sun freak, though it would probably be pushing my luck to describe a man who compulsively visits circus sideshows as a freak freak (ZINSSER, 2006, p. 37).
Este é o segundo parágrafo do capítulo que requer maior número de adaptações para o idioma português. Na tradução de Ajzenberg o leitor pode ler:

Referi-me, há pouco, a um episódio em que universitários azucrinavam a direção de uma faculdade e, no capítulo precedente, revelei ser um maníaco por palavras. Pois aí se encontram, justamente, duas recémchegadas. 0 verbo 'azucrinar' significa perturbar uma pessoa, e quem quer perturbar uma pessoa, e quem quer que já tenha sido azucrinado por um funcionário por não conseguir preencher um formulário corretamente haverá de concordar que essa palavra cai como uma luva. 'Maníaco', no caso, significa um entusiasta das palavras, e isso não tira a aura de obsessão que se subentende ao chamarmos alguém de maníaco por jazz, ou maníaco por xadrez, ou maníaco por sol, embora provavelmente eu corresse o risco de me dar mal se tentasse descrever uma pessoa que frequenta compulsivamente hospitais psiquiátricos como um maníaco por maníacos (ZINSSER, 2017, p. 55).

Neste mesmo parágrafo, temos cinco elementos que requerem adaptação, sendo que um deles demandou a observação em nota do tradutor. Trata-se da palavra hassle que, dessa forma, Ajzenberg revela ter sido o termo utilizado no texto original e que ele traz o sentido de disputa e controvérsia. Sendo assim, o leitor compreende que tal termo vem de uma definição formal, mas que já passou a ser utilizado de maneira informal, que traz o sentido de incomodar, e que na tradução ficou como "azucrinar", aproximando-se da temática do capítulo, onde se discute o emprego de certas palavras em textos de não ficção.

Em seguida, temos o termo freak: apesar de ter tomado o caminho para um estrangeirismo no nosso vocabulário, ainda se faz necessário encontrar sua correspondência de acordo com o contexto. Ajzenberg utilizou a palavra "maníaco" levando em consideração o sentido desejado pelo texto original, remetendo ao termo coloquial que caracteriza alguém com grande entusiasmo em relação a algo. Ao final do parágrafo, no entanto, 
foi preciso fazer uma adaptação cultural referente ao contexto americano dos freak shows antigamente produzidos por circos mambembes, que traziam tipos humanos grotescos e considerados "monstruosos", sendo este termo também sinônimo para freak. Na ausência do emprego dessa palavra para situação correspondente em português no contexto circense, a solução para a tradução foi a alteração do cenário para o de um hospital psiquiátrico.

Ainda temos o termo técnico Form 35-BX usado para designar um tipo específico de formulário. Em português não ocorre prejuízo algum ao se suprimir as siglas, mantendo apenas a palavra "formulário". Por fim, a expressão pushing my luck também foi coerentemente traduzida como "correr o risco de me dar mal".

No capítulo intitulado "Palavras", o autor lança mão de palavras que são de fácil uso para alguns profissionais, como os jornalistas que, de uma hora para outra, passam a empregar "uma mistura de palavras vulgares, palavras inventadas e chavões tão difundidos que dificilmente um escritor consegue evitar o seu uso" (ZINSSER, 2017, p.49). É o que o autor chama de "jornalês" (journalese). Ao exemplificar algumas dessas palavras, como substantivos que acabaram por dar origem a verbos inusitados, Zinsser, no original, dá o exemplo to host, o que exigiu uma adaptação contextual para o nosso idioma, tendo a tradução brasileira os verbos "impactar" e "pedagiar". Outros exemplos do mesmo fenômeno linguístico se referem a substantivos mutilados para formar verbos, dados os exemplos enthuse e emote (substituídos na tradução por "impeachar" e "googlar"). Em momentos em que os exemplos são phrasal verbs (beef up e put teeth into), não há correspondente algum na língua de chegada, de modo que foram excluídos da tradução.

Enquanto o livro discorre sobre usos de palavras que atravessaram ou não o "portal do bom uso", a tradução precisou encontrar meios semelhantes para o entendimento do leitor brasileiro, em especial nas situações em que Zinsser faz da informação um pretexto para a construção do seu próprio discurso teórico, como em momentos em que ele o faz usando a ironia. Ao abordar a utilização do ain't (am not e are not) e a permissividade do dicionário Webster em considerá-lo já aceitável por ser usado oralmente na maior parte dos EUA, Zinsser (2006, p. 40) questiona: "Just where Webster cultivated those speakers I ain't sure.", traduzido como "Onde é que o Webster encontrou esses falantes, eu não tenho ideia", seguido da nota explicativa do tradutor: "I ain't sure, usado ironicamente pelo autor" (2017, p. 60).

0 mesmo ocorre quando o autor pondera sobre o uso de preposições nos finais de frases e, ao dar sua opinião favorável sobre esta prática, conclui: "I think a sentence is a fine thing to put a preposition at the end of" (2006, p. 41). A tradução da frase é adequada, mas não alcança o mesmo efeito em português, pela própria impossibilidade de se manter a mesma construção gramatical: "Eu acredito que o final da frase em inglês é um ótimo lugar onde colocar uma preposição", traduz Ajzenberg, trazendo para a nota de rodapé a frase original e esclarecendo o efeito desejado pelo autor.

Assim como essas, existem outras passagens em que a devida adaptação, explicação ou supressão foram necessárias para manter o entendimento técnico ou a coerência no texto traduzido, garantindo a compreensão do leitor brasileiro.

A publicação de uma importante obra como essa no Brasil, traduzida com tal consciência, favorece não apenas as práticas de aprendizado e aperfeiçoamento de novos escritores de não ficção, como amplia o importante e ainda escasso debate acadêmico em torno deste gênero que tangencia o jornalismo como prática literária, assim como as diferentes propostas literárias de não ficção, como as memórias, as biografias, as longas reportagens, os perfis, as reportagens de viagem e o próprio Jornalismo Literário como disciplina acadêmica. Por esse mesmo motivo, é 
de se alimentar a expectativa de novas edições com a inclusão dos capítulos originais ainda não traduzidos nessa primeira edição brasileira.

\section{Referências}

DIXELER, Elsa. On On writing well. The New York Times. New York, 19 mar. 2009.

Disponível em: https://artsbeat.blogs.nytimes.com/2009/03/19/on-on-writing-well/.

Acesso em: 22 jan. 2018.

ZINSSER, William. Como escrever bem. Tradução: Bernardo Ajzenberg. São Paulo: Três Estrelas, 2017.

ZINSSER, William. On writing well. New York: HarperCollins, 2006.

Recebido em: 6/7/2018.

Aprovado em: 20/11/2018.

Publicado em: 15/6/2019. 